\title{
Dynamic Cubic Illuminance: An Example of Application of a New Paradigm for Daylight Analysis in an Ancient Pompeian Domus
}

\author{
Juan Manuel Monteoliva ${ }^{1,2}$, Francesca Fragliasso ${ }^{3}$, Laura Bellia ${ }^{3}$, Andrea Pattini ${ }^{1}$ \\ ${ }^{1}$ INAHE, CONICET, Mendoza, Argentina \\ ${ }^{2}$ Facultad de Artes y Diseño, Universidad Nacional de Cuyo, Centro Universitario M5502JMA, \\ Mendoza, Argentina \\ ${ }^{3}$ Department of Industrial Engineering of the University of Naples "Federico II, Naples, Italy
}

\begin{abstract}
The paper presents an analysis methodology to dynamically assess daylight characteristics in indoor environments, based on the combination of bidimensional indicators (i.e. indicators based on the traditional illuminance calculation) with threedimensional ones (based on the concept of the Cubic Illumination). For this purpose, the Useful Modeling Indices (UMIs) are introduced. The method is applied to two particular case-studies: the atrium and the peristyle in the Villa of the Mysteries in Pompeii. These architectural structures, being conceived as filtering spaces to attenuate entering daylight, represent a particularly interesting field of research.
\end{abstract}

\section{Introduction}

Today, advances in the field of numerical analysis of daylighting performance in buildings have enabled to gain in-depth knowledge about photometric assessment of daylight quality.

Light quality is indirectly explored by considering different aspects: quantity of light (illuminance and luminance), distribution of light (uniformity, luminance distribution), glare (disability glare, discomfort glare, veiling reflections), spectral power distribution of light (color appearance, light color quality), daylight (daylight penetration, outside view), directionality of light (direction and modeling), and dynamics (variability and rhythm) (Kruisselbrink et al., 2018).

These aspects can be assessed by means of specific performance indicators and several attempts have been developed to generate models of unique indices, capable of evaluating and describing this construct (Boyce, 2013): the visibility level model, the lighting quality index, the comfort, satisfaction and performance index, the interior lighting evaluation system and the ergonomic lighting indicator. However, all of the abovementioned indicators have significant limitations.

In recent years, dynamic daylight paradigm has resulted in the significant progress in assessing daylight dynamically and in the proposal of new indicators - such as UDI (Nabil \& Mardaljevic, 2005) DA and DAcon (Reinhart et al., 2006), sDA and ASE (IES LM-83-12 -. New indicators are mainly based on the analysis of the annual trends of daylight illuminances. Illuminance is essentially a two-dimensional concept, insofar as it is concerned with the density of luminous flux incident at a point on a surface. However, as it was previously mentioned, when assessing light, it is fundamental to consider not only quantitative aspects, but also qualitative ones, accounting for directionality and spatial distribution in the three dimensions of the space. Consequently, new advances in the definition of spatial illumination metrics are necessary, in order to consider that, given a point, the light reaching it has different effects depending on the incidence direction. So, considering differently oriented planes, all containing the point, illuminances referred to each plane can assume values more or less divergent depending on the spatial light distribution. The comparison among these illuminance values can be useful to have an idea of the three-dimensional light patterns.

Based on these concepts, various three-dimensional illuminance metrics have been proposed over the past three decades, to describe what Lynes et al. (1966) referred to as the vectorial flow of light within architectural environments: the modeling ratio, the mean cylindrical and semicylindrical illuminances, the scalar (mean spherical) illuminance, the semi-scalar (mean hemispherical) illuminance, the vectorial illuminance, the vector-to-scalar illuminance ratio, and the cubic illumination (Ashdown, 1998). One of the most thorough descriptions and explanations about these indices has been given by Cuttle $(1997,2008,2014)$ and later rewritten in different books and journals.

Cuttle proposes the underlying principle of cubic illuminance (Cuttle, 1997). The cubic illuminance is based on the idea to calculate illuminance values referred to the surfaces of a cube. These surfaces are aligned parallel to the $\mathrm{x}, \mathrm{y}$ and $\mathrm{z}$ axes, and the illuminances referred to the six surfaces are specified $-\mathrm{E}_{(\mathrm{x})}, \mathrm{E}_{(-\mathrm{x})}, \mathrm{E}_{(\mathrm{y})}, \mathrm{E}_{(-}$ $\mathrm{y}), \mathrm{E}_{(\mathrm{z})}$ and $\mathrm{E}_{(-\mathrm{z})^{-}}$so that $\mathrm{E}_{(\mathrm{z})}$ is the familiar horizontal illuminance. These measured or predicted illuminance values on the facets of a cube enable the estimation of a range of spatial illumination metrics. These metrics (vector to scalar ratio; cylindrical to horizontal illuminance ratio, vector to cylindrical illuminance ratio, and vertical to horizontal illuminance ratio) are useful to assess modeling of faces and environments, as described by Kruisselbrink et al. (2018).

Recently, Monteoliva et al. (2018) have proposed to apply the principles of the cubic illumination into the paradigm of dynamic simulation, through a new concept: useful modeling indices (UMIs). UMIs make it possible to 
quantify annual occurrence of proper light modeling conditions. The perception of volume, texture and the intensity of colors also depend on the direction of light. It is important to consider that this dynamic methodology can be applied to different modeling indicators that arise from the information obtained from cubic illuminance, such as: vector to scalar ratio, vector to cylindrical illuminance ratio, and vertical to horizontal illuminance ratio.

In this paper, these indices are used to evaluate daylighting conditions in one of the most famous ancient Pompeian domus: Villa of the Mysteries.

Indeed, in this context, Roman Villas represent a very stimulating research field. Ancient architects carefully considered daylighting (Paoli, 2006), despite the limited use of transparent materials due to the scarce availability and costs for glass panes or very thick gypsum layers. For this reason, also owing to the Mediterranean sunny climate, "patios" (atria and peristyles) represented architectural solutions able to mitigate the entrance of daylight in the inner spaces of the houses and at the same time to serve as "smart" connection between indoor and outdoor spaces, by properly shadowing and attenuating light distribution.

Based on these premises, the paper aims at assessing daylight characteristics of two spaces in the Villa of the Mysteries: one of the atria and the peristyle. For this purpose the annual occurrence of desired daylighting conditions was assessed by means of a modeling performance indicator: the useful vector to scalar ratio $\left(\mathrm{u}|\mathbf{E}| / \mathrm{E}_{\mathrm{sr}(0.1-0.2)}\right)$. This method estimates the annual occurrence (\%) of the $|\mathbf{E}| / \mathrm{E}_{\mathrm{sr}}$ ratio in the range 0.1-0.2 for the selected node. Furthermore, this procedure can be linked to dynamic daylight analysis with traditional metrics based on illuminances, in order to better evaluate the quality of daylighting.

\section{Methods}

This section is divided into three main sections: Spaces description, Daylight simulation, and Dynamic daylight performance metrics assessment.

\section{Spaces description}

As it was reported in the Introduction, in this work Villa of the Mysteries, located in Pompeii, $23 \mathrm{~km}$ from the city of Naples (Italy) (Latitude $40^{\circ} 45^{\prime} \mathrm{N}$; Longitude $14^{\circ} 28^{\prime}$ E), was chosen for daylight analyses (see Figure 1).

It is a suburban Villa located outside the north walls of the ancient city, on a sloped plot of land, chosen because of the wonderful panorama it faced. The Villa was completely brought to light in 1929-1930 by Amedeo Maiuri and its original nucleus dates back to the first half of the II century B.C. (Maiuri, 1931). The current shape of the Villa is the result of several refurbishment works, performed over time till the Vesuvius eruption in 79 A.C. The building has a complex structure keeping together both characteristic spaces of a typical Villa d'otium and those proper of the Villa rustica. Thanks to the good state of conservation, it is possible to almost easily suppose the shape of the Villa before the eruption and to build its virtual model (see Figure 1).

The daylight analysis was focused on two spaces in the Villa characterized by direct daylight penetration: (a) the Peristyle: $21.9 \mathrm{~m} \mathrm{x} 15 \mathrm{~m}\left(328.5 \mathrm{~m}^{2}, 92.8 \mathrm{~m}^{2}\right.$ of which covered), and (b) one of the atria: $7.2 \mathrm{~m} \mathrm{x} 7.4 \mathrm{~m}(53.28$ $\mathrm{m}^{2}, 39.8 \mathrm{~m}^{2}$ of which covered).

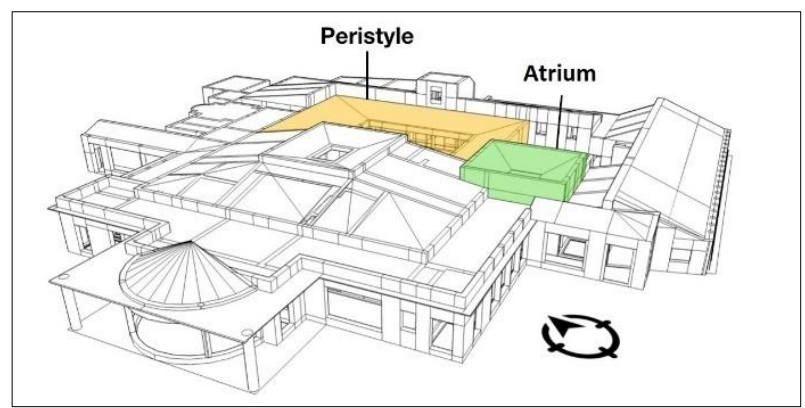

Figure 1: General view of the Villa of the Mysteries. Render images of (a) Peristyle and (b) Atrium in the $3 D$ model

\section{Daylight simulation}

The CAD model of the Villa of the Mysteries was generated with Trimble SketchUp Make v. 2015. It has Ruby code language, an interpreted, reflexive and objectoriented programming language, which makes it easier for users to generate program segments to modify its functionality. Within this code language, the Warehouse Groundhog extension (Molina et al., 2008) Open Source v.3 (GPLv3) was used for making 3D models compatible with the RADIANCE environment. RADIANCE (Ward \& Rubinstein, 1988) is a highly accurate raytracing software, considered to be one of the most powerful and popular forms of lighting simulation software and it has been extensively validated in the last 20 years (Berardi \& Wang, 2014).

The photometric characterization of the interior materials of the spaces was entered according to measured reflectance and color values published in a previous work (Bellia et al., 2017): (i) Walls (Medium Concrete (rho = $0.204)$, Dark yellow $($ rho $=0.261)$, Yellow $($ rho $=0.343)$, Dark red $($ rho $=0.099)$, Red $($ rho $=0.162)$, Black $($ rho $=$ $0.0)$, Multicolor average $($ rho $=0.118)$, Red Brick $($ rho $=$ 0.138 ); (ii) Floor (Black and white (rho $=0.42)$ ); (iii) Ceiling (Dark Wood (rho $=0.227)$ ); and (iv) Outground $($ Greenish Grass $($ rho $=0.102)$ ).

Simulations were performed using the weather data file referred to Naples (Latitude $40^{\circ} 51^{\prime} \mathrm{N}$; Longitude $14^{\circ} 16^{\prime}$ E), downloaded by Energy Plus web-site (ITA_Naples.162890_IWEC), since currently a weather data file specific for Pompeii (Latitude $40^{\circ} 45^{\prime} \mathrm{N}$; Longitude $14^{\circ} 28^{\prime}$ E) does not exist.

The simulation parameters used in RADIANCE correspond to Jacobs' accurate scene (Jacobs, 2012): (ab) 5; (ad) 2048; (as) 512; (aa) 0.08; (ar) 512; (dt) 0; (ds) 0. The simulation was performed for all the hours of the day 
characterized by availability of solar radiation as reported in the chosen weather data file (see Figure 2).

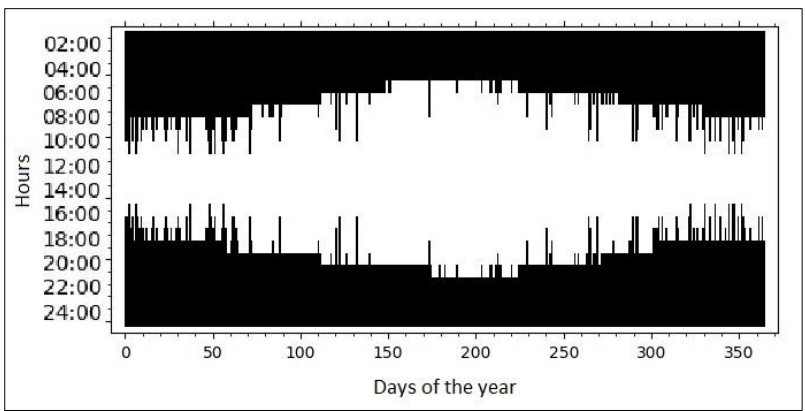

Figure 2: Scheduling used for dynamic daylight simulations

\section{Dynamic daylight performance metrics assessment}

Daylighting was evaluated by means of both twodimensional metrics and three-dimensional ones. On one hand, from two horizontal grids of 308 sensors and 70 sensors $(\mathrm{h}=0.8 \mathrm{~m})$ located in the Peristyle and the Atrium (see Figure 1) respectively, it was possible to evaluate the dynamic spatial daylight autonomy (sDA). As proposed by the IES LM-83-12, the sDA represents the percentage of the area that meets a given Daylight Autonomy (generally 50\%) for a set analysis period, referring to a specific illuminance level (for example $300 \mathrm{~lx}$ ). The illuminance level considered as target is chosen depending on the visual task performed in the analyzed space. When the function of the space is not specified, 300 $1 \mathrm{x}$ can represent a proper value, being generally prescribed for not particularly accurate visual tasks. As regards this application, the atrium and the peristyle are two circulating areas, so, according to modern design criteria reported in the EN 12464-1 standard, the task illuminance should be equal to $100 \mathrm{~lx}$. However, as it was previously mentioned, the analyzed spaces were conceived by ancient Romans as interfaces between outdoor and indoor, so they can be classified as a sort of semi-outdoor spaces receiving a big amount of daylight and being often lit by direct sunlight. Consequently, they are generally characterized by illuminance levels much higher than 100 lx. sDA referred to $100 \mathrm{~lx}$ (and to $300 \mathrm{~lx}$ as well) would be equal to $100 \%$, being not significant to describe the spaces. For this reason, authors decided to calculate sDA according to a higher target, i.e. 1000 lx.

On the other hand, in each one of the spaces four positions located under the arcades, at a distance from the floor equal to $1.2 \mathrm{~m}$, were selected: position 1 (under the north arcade), position 2 (under the east arcade), position 3 (under the south arcade), position 4 (under the west arcade); obtaining in this way a total of 8 evaluation positions (see Figures 3 and 4).

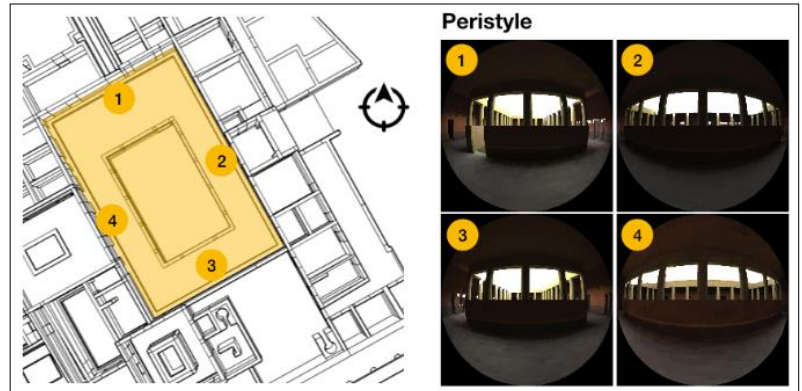

Figure 3: Selected positions for the three-dimensional metrics analysis in the Peristyle

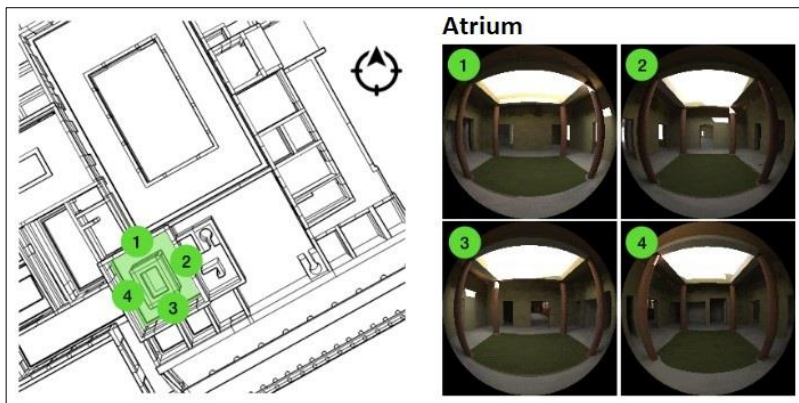

Figure 4: Selected positions for the three-dimensional metrics analysis in the Atrium

Subsequently, the cubic illuminance $\left(\mathrm{E}_{\text {cubic }}=\mathrm{E}_{(\mathrm{x})}, \mathrm{E}_{(\mathrm{y})}\right.$, $\left.\mathrm{E}_{(\mathrm{z})}, \mathrm{E}_{(-\mathrm{x})}, \mathrm{E}_{(-\mathrm{y})}, \mathrm{E}_{(-\mathrm{z})}\right)$ was analyzed for each one of the positions. It must be underlined that, even though the two principal axes of the Villa are not perfectly oriented according to the north-south and east-west directions (see Figure 1), the $\mathrm{x}$ and $\mathrm{y}$ directions considered for cubic illuminance calculations are the very north-south and east-west axes, corresponding to the Cartesian coordinates used both in RADIANCE and in Sketchup.

By calculating cubic illuminance, it was possible to acquire for each position in both spaces, the vertical illuminances $\left(\mathrm{E}_{\mathrm{vertical}}\right)$, i.e. the illuminances referred to the surfaces oriented towards north $\left(\mathrm{E}_{(\mathrm{y})}\right)$, east $\left(\mathrm{E}_{(\mathrm{x})}\right)$, south $\left(\mathrm{E}_{(-\mathrm{y})}\right)$ and west $\left(\mathrm{E}_{(-\mathrm{x})}\right)$ and the horizontal illuminance $\left(\mathrm{E}_{(\mathrm{z})}\right)$.

Then three-dimensional metrics were calculated. The concept of useful modeling indices (UMIs) was used for this study (Monteoliva et al., 2018). This is an approach to quantify the annual occurrence of desired daylighting conditions using modeling performance indicators. In this particular case UMIs is applied to the static paradigm indicator called vector to scalar ratio $\left(|\mathbf{E}| / \mathrm{E}_{\mathrm{sr}}\right)$, making it the useful vector to scalar ratio $\left(\mathrm{u}|\mathbf{E}| / \mathrm{E}_{\mathrm{sr}(0.1-0.2)}\right)$.

First of all, it was necessary to calculate the static $|\mathbf{E}| / \mathrm{E}_{\mathrm{sr}}$ for each position and for each record of the weather data file, according to the following calculation procedure.

The illuminance vector $\mathbf{E}$ components on each of the cubic axes therefore are:

$$
{ }^{\prime} E_{(x)}=E_{(+x)}-E_{(-x)}
$$




$$
\begin{aligned}
& { }^{\prime} E_{(y)}=E_{(+y)}-E_{(-y)} \\
& { }^{\prime} E_{(z)}=E_{(+z)}-E_{(-z)}
\end{aligned}
$$

The vector sum is also a vector $\left(\left|\mathbf{E}_{(\mathrm{x}, \mathrm{y}, \mathrm{z})}\right|\right)$ with the illuminance as magnitude $(|\mathbf{E}|)$ (Ashdown, 1998). The direction of the illumination vector is the altitude angle generated between the maximum and minimum luminance rays (Ashdown, 1998; Cuttle, 1997).

$$
\left|E_{(x, y, z)}\right|=\sqrt{{ }^{\prime} E_{(x)}^{2}+{ }^{\prime} E_{(y)}^{2}+{ }^{\prime} E_{(z)}^{2}}
$$

This intensity of luminous flux is described by the magnitude of the illumination vector with respect to the total amount of incident light in this infinitesimal sphere, also called scalar illumination, $\mathrm{E}_{\mathrm{sr}}$, (5) (Lynes et al. 1966). To reach this value it is necessary to calculate previously symmetric components on the $\mathrm{x}, \mathrm{y}$ and $\mathrm{z}$ axes (3); and symmetric illuminance (4).

$$
\begin{gathered}
\sim E_{(x)}=\frac{E_{(+x)}+E_{(-x)}-\left|E_{(x)}\right|}{2} \\
\sim E=\frac{\sim E_{(x)}+\sim E_{(y)}+\sim E_{(z)}}{3} \\
E_{s r}=\sim E+\frac{|E|}{4}
\end{gathered}
$$

Finally, it is possible to calculate the vector to scalar ratio:

$$
|E| / E_{s r}
$$

According to Cuttle (2008), based on the values assumed by $|\mathbf{E}| / E_{\text {sr }}$ it is possible to evaluate the light modeling characteristics since the perception of volume, texture and colors also depends on the direction of light. Specifically, we can distinguish (a) weak modeling $\left(|\mathbf{E}| / \mathrm{E}_{\mathrm{sr}}<0.1\right)$ : it happens when the volume of the face shows low contrast, produced mainly by diffuse light; (b) moderate modeling $\left.\left(0.1<|\mathbf{E}| / \mathrm{E}_{\mathrm{sr}}<0.2\right)\right)$ : it appears when the volume of the face shows a pleasant and well balanced contrast and threedimensional volumes are perceived with details and textures; (c) strong modeling $\left(|\mathbf{E}| / \mathrm{E}_{\mathrm{sr}}>0.2\right)$ : it occurs when the volume shows an excessive contrast with very dark shadows over the face, caused by a source of light with a strong directional component.

Based on these premises the UMIs method estimates the annual occurrence (\%) of $|\mathbf{E}| / \mathrm{E}_{\mathrm{sr}}$ in the range 0.1-0.2 in the selected node. Then the annual occurrences of $|\mathbf{E}| / \mathrm{E}_{\mathrm{sr}}$ lower than 0.1 and higher than 0.2 are evaluated as well.

Differently from the two-dimensional metrics, the UMI allows evaluating the light quality in a space, accounting for its modeling effects, overcoming the typical quantitative evaluation approach based on the calculation

of the illuminance levels at a surface. In this way it is possible to have an idea not only about the quantity of light entering a space, but about its quality in terms of balance between diffuse and direct light. When daylight is implied, this means to evaluate the relationship between diffuse daylight (skylight and reflected daylight) and direct sunlight.

\section{Results}

\section{Two-dimensional metrics}

When evaluating the horizontal grid with the dynamic metric sDA (10001x, 50\%), the results for both spaces have a similar percentage of daylight availability area, obtaining $66.56 \%$ and $57.89 \%$ in the Peristyle and Atrium, respectively.

Analyzing the average vertical illuminances in the four orientations $\left(\mathrm{E}_{(\mathrm{x})}, \mathrm{E}_{(-\mathrm{x})}, \mathrm{E}_{(\mathrm{y})}, \mathrm{E}_{(-\mathrm{y})}\right)$, we can see that the Peristyle presents the highest average annual values in points 1, 2 and 4, highlighting the vertical illuminances related to the surfaces oriented to the South $\left(\mathrm{E}_{(-\mathrm{y})}=1375\right.$ $1 \mathrm{x})$, West $\left(\mathrm{E}_{(-\mathrm{x})}=15921 \mathrm{x}\right)$, and East $\left(\mathrm{E}_{(\mathrm{x})}=1643 \mathrm{~lx}\right)$, respectively (see Table 1 and Figure 5). In the other positions and directions, $\mathrm{E}_{\text {vertical }}$ values are always lower than $1000 \mathrm{~lx}$.

Table 1: Results of the dynamic simulation $\left(E_{\text {cubic }}\right)$ in the Peristyle

\begin{tabular}{|c|c|c|c|c|c|c|c|}
\hline \multicolumn{7}{|c|}{ Peristyle } \\
\hline \multicolumn{3}{|c|}{ Position 1 } & \multicolumn{5}{|c|}{ Position 2 } \\
\hline $\boldsymbol{E}_{(x)}$ & 694 & $\boldsymbol{E}_{(-x)}$ & 170 & $\boldsymbol{E}_{(x)}$ & 168 & $\boldsymbol{E}_{(-x)}$ & 1592 \\
\hline $\boldsymbol{E}_{(y)}$ & 92 & $\boldsymbol{E}_{(-\boldsymbol{y})}$ & 1375 & $\boldsymbol{E}_{(\boldsymbol{y})}$ & 351 & $\boldsymbol{E}_{(-y)}$ & 986 \\
\hline $\boldsymbol{E}_{(z)}$ & 397 & $\boldsymbol{E}_{(-z)}$ & 531 & $\boldsymbol{E}_{(z)}$ & 484 & $\boldsymbol{E}_{(-z)}$ & 486 \\
\hline \multicolumn{3}{|c|}{ Position 3 } & \multicolumn{5}{c|}{ Position 4 } \\
\hline $\boldsymbol{E}_{(x)}$ & 44 & $\boldsymbol{E}_{(-x)}$ & 283 & $\boldsymbol{E}_{(x)}$ & 1643 & $\boldsymbol{E}_{(-x)}$ & 270 \\
\hline $\boldsymbol{E}_{(y)}$ & 734 & $\boldsymbol{E}_{(-y)}$ & 112 & $\boldsymbol{E}_{(y)}$ & 1038 & $\boldsymbol{E}_{(-y)}$ & 231 \\
\hline $\boldsymbol{E}_{(z)}$ & 154 & $\boldsymbol{E}_{(-z)}$ & 128 & $\boldsymbol{E}_{(z)}$ & 612 & $\boldsymbol{E}_{(-z)}$ & 603 \\
\hline
\end{tabular}

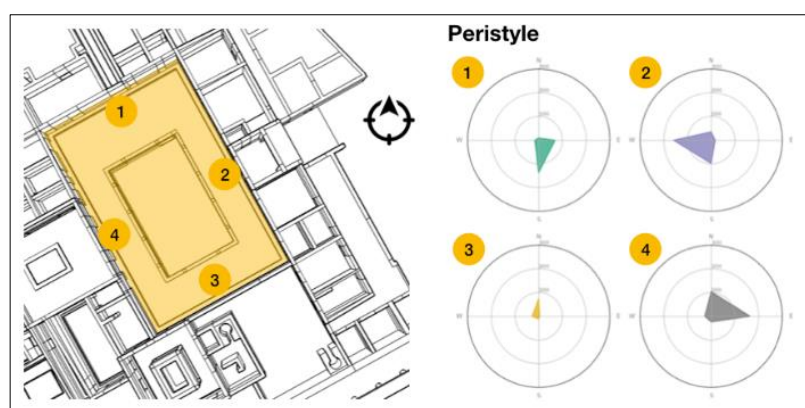

Figure 5: Results of distribution of average vertical illuminances in point 1, 2, 3 and 4 in the Peristyle

This result can be explained considering that the point 3 is the one located under the south arcade of the peristyle and it receives direct daylight from North. On the 
contrary, Positions 1, 2 and 4 receive direct daylight from South, West and East respectively.

In relation to the average annual horizontal illuminance (i.e. $\mathrm{E}_{(\mathrm{z})}$ ), position 4 stands out with an $\mathrm{E}_{(\mathrm{z})}=612 \mathrm{~lx}$, being $\mathrm{E}_{(\mathrm{z})}$ values always lower than $500 \mathrm{~lx}$ for all the other positions.

An interesting aspect deserving being underlined is that, for all four of the positions, there is always a significant difference between results related to $\mathrm{E}_{(\mathrm{x})}$ and $\mathrm{E}_{(-\mathrm{x})}$ and to $\mathrm{E}_{(\mathrm{y})}$ and $\mathrm{E}_{(-\mathrm{y})}$. This means that the light conditions perceived by an observer located in correspondence of the calculation point, would be very different depending on his direction of view. This is due to the fact that the analyzed space is a passage between outside and inside and direct daylight comes only from one direction. Considering the $(\mathrm{z})$ and the $(-\mathrm{z})$ axes, the related illuminances are quite similar. This is probably due to the fact that the light reflected by the floor has a significant incidence in determining the $\mathrm{E}_{(-\mathrm{z})}$.

The results in the Atrium (see Table 2 and Figure 6) show the highest average vertical illuminances in points 1 and 2, highlighting for the first position the illuminances referred to the surfaces directed towards South $\left(\mathrm{E}_{(-\mathrm{y})}=\right.$ $37451 \mathrm{x})$ and East $(\mathrm{E}(\mathrm{x})=1973 \mathrm{~lx})$, and for the second position towards the South $(\mathrm{E}(-\mathrm{y})=1918 \mathrm{~lx})$ and West $(\mathrm{E}(-\mathrm{x})=3746 \mathrm{~lx})$. In both positions, all the other vertical illuminances assume values lower than 1000 lx. Likewise, positions 3 and 4 present for all orientations $E_{\text {vertical values }}$ lower than $1300 \mathrm{~lx}$, except for point 3, characterized by an $\mathrm{E}_{(\mathrm{y})}$ value equal to $1434 \mathrm{~lx}$ and point 4 characterized by an $\mathrm{E}_{(\mathrm{x})}$ value equal to $\left.1795 \mathrm{~lx}\right)$. In relation to $\mathrm{E}_{(\mathrm{z})}$, points 1 and 2 present a similar condition, with $\mathrm{E}_{(\mathrm{z})}$ values higher than $2500 \mathrm{~lx}$, while for points 3 and $4 \mathrm{E}_{(\mathrm{z})}$ is lower than 1100 $1 \mathrm{x}$.

Therefore, contrary to what previously observed, in the case of the atrium differences between the illuminances evaluated according to the positive and the negative axes are quite significant not only for $\mathrm{x}$ and $\mathrm{y}$ directions, but also for the $\mathrm{z}$ one as well.

Table 2: Results of the dynamic simulation $\left(E_{\text {cubic }}\right)$ in the Atrium

\begin{tabular}{|c|c|c|c|c|c|c|c|}
\hline \multicolumn{7}{|c|}{ Atrium } \\
\hline \multicolumn{3}{|c|}{ Position 1 } & \multicolumn{5}{c|}{ Position 2 } \\
\hline $\boldsymbol{E}_{(\boldsymbol{x})}$ & 1973 & $E_{(-x)}$ & 744 & $\boldsymbol{E}_{(x)}$ & 767 & $E_{(-x)}$ & 3746 \\
\hline $\boldsymbol{E}_{(\boldsymbol{y})}$ & 692 & $E_{(-y)}$ & 3745 & $\boldsymbol{E}_{(\boldsymbol{y})}$ & 653 & $E_{(-y)}$ & 1918 \\
\hline $\boldsymbol{E}_{(z)}$ & 2981 & $E_{(-z)}$ & 1701 & $\boldsymbol{E}_{(z)}$ & 2628 & $E_{(-z)}$ & 1254 \\
\hline \multicolumn{3}{|c|}{ Position 3 } & \multicolumn{5}{c|}{ Position 4 } \\
\hline $\boldsymbol{E}_{(x)}$ & 332 & $E_{(-x)}$ & 607 & $\boldsymbol{E}_{(x)}$ & 1795 & $E_{(-x)}$ & 1201 \\
\hline $\boldsymbol{E}_{(\boldsymbol{y})}$ & 1434 & $E_{(-y)}$ & 188 & $\boldsymbol{E}_{(\boldsymbol{y})}$ & 1035 & $E_{(-y)}$ & 716 \\
\hline $\boldsymbol{E}_{(z)}$ & 809 & $E_{(-z)}$ & 510 & $\boldsymbol{E}_{(z)}$ & 1095 & $E_{(-z)}$ & 822 \\
\hline
\end{tabular}

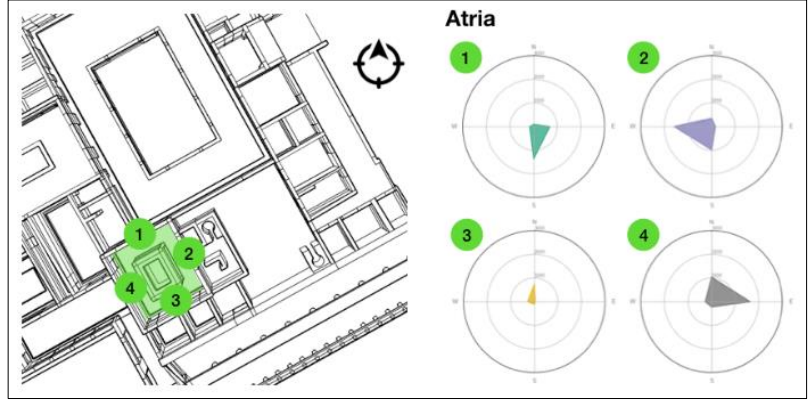

Figure 6: Results of distribution of average vertical illuminances in point 1, 2, 3 and 4 in the Atrium

\section{Three-dimensional metrics}

In the Peristyle, when analyzing $\mathrm{u}|\mathbf{E}| / \mathrm{E}_{\mathrm{sr}(0.1-0.2)}$ values (see Table 3), it can be observed that positions 1, 2 and 3 present annual values lower than $3 \%$. That is to say that in these points, only $3 \%$ of the year (132 hours) is characterized by moderate modeling conditions ( 0.1 $\left.<|\mathbf{E}| / \mathrm{E}_{\mathrm{sr}}<0.2\right)$. Likewise, point 4 in the Peristyle, is the position with the greatest occurrence of useful conditions $\left(\mathrm{u}|\mathbf{E}| / \mathrm{E}_{\mathrm{sr}(0.1-0.2)}=57.34 \%\right)$. The occurrence of default and excess conditions show that all positions have strong modeling as the predominant condition $(|\mathbf{E}| / E s r>0.2)$, obtaining annual percentages always higher than $97 \%$ in the points 1,2 and 3 and higher than $40 \%$ in point 4 . This determines that the weak modeling condition $\left(\mathrm{u}|\mathbf{E}| / \mathrm{E}_{\mathrm{sr}(<0.1)}\right)$ presents annual values lower than $10 \%$. From the dynamic modeling methodology (see Figure 7) it is possible to observe that in point 1 the conditions of $\mathrm{u}|\mathbf{E}| / \mathrm{E}_{\mathrm{sr}(>0.2)}$ is relatively constant throughout the year, highlighting extreme conditions $\left(|\mathbf{E}| / \mathrm{E}_{\mathrm{sr}}>0.3\right)$ in the halfseason period during the first hours of the morning until noon. However, this condition in position 2 occurs from noon until 6:00 p.m. approximately $\left(\mathrm{E}_{\mathrm{sr}(>0.2)}=97.48 \%\right)$. Regarding point 3, a behavior similar to point 1 can be observed. However, it does not present significant extreme conditions. Finally, position 4 , as it was mentioned, presents moderate modeling conditions for most of the year, highlighting the strong modeling conditions $(41.85 \%)$ in the summer period from the first hours of the morning until midday.

Table 3: $u|\boldsymbol{E}| / E_{s r(0.1-0.2)}$ values in positions 1, 2, 3 and 4 referred to the Peristyle

\begin{tabular}{|c|c|c|c|}
\hline & \multicolumn{3}{|c|}{ Peristyle } \\
\cline { 2 - 4 } & $\mathbf{u}|\mathbf{E}| / \mathbf{E}_{\mathbf{s r}(<\mathbf{0 . 1})}$ & $\mathbf{u}|\mathbf{E}| \mathbf{E}_{\mathbf{s r}(\mathbf{0 . 1}-\mathbf{0 . 2})}$ & $\mathbf{u}|\mathbf{E}| \mathbf{E}_{\mathbf{s r}(>\mathbf{0 . 2})}$ \\
\hline Position 1 & $0.00 \%$ & $0.72 \%$ & $99.28 \%$ \\
\hline Position 2 & $0.26 \%$ & $2.26 \%$ & $97.48 \%$ \\
\hline Position 3 & $0.17 \%$ & $0.48 \%$ & $99.35 \%$ \\
\hline Position 4 & $0.81 \%$ & $57.34 \%$ & $41.85 \%$ \\
\hline
\end{tabular}




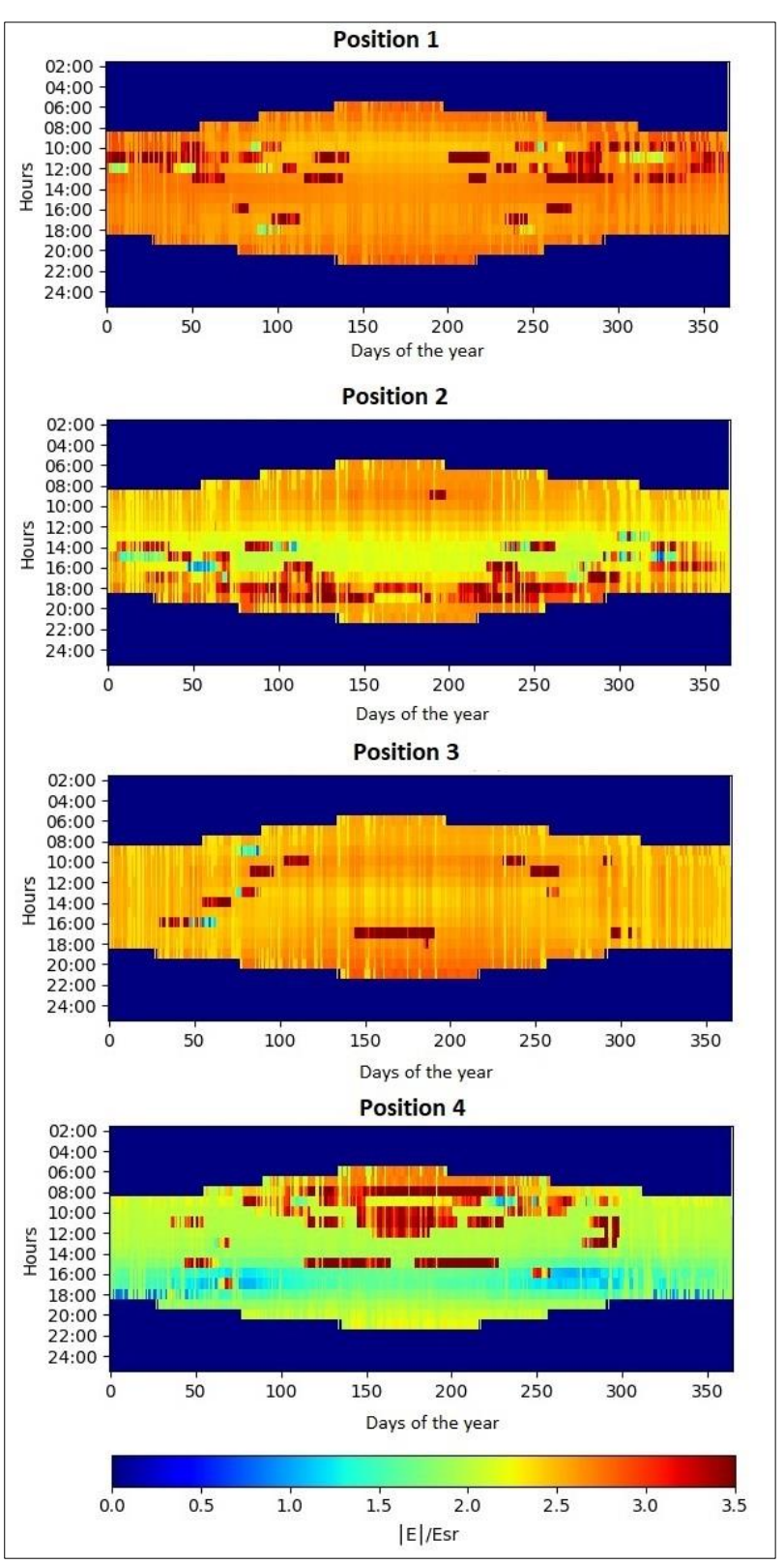

Figure 7: $|\boldsymbol{E}| / E_{s r}$ annual trends in positions 1, 2, 3 and 4 referred to the Peristyle

When analyzing the Atrium (see Table 4), a greater annual occurrence of the moderate modeling condition is observed, in relation to the Peristyle, in most of the positions except point $2\left(\mathrm{u}|\mathbf{E}| / \mathrm{E}_{\mathrm{sr}(0.1-0.2)}=8.51 \%\right)$.

Table $4-u|\boldsymbol{E}| / E_{s r(0.1-0.2)}$ values in positions $1,2,3$ and 4 referred to the Atrium

\begin{tabular}{|l|l|l|l|}
\hline & \multicolumn{2}{|l|}{ Atrium } \\
\cline { 2 - 4 } & $\mathbf{u}|\mathrm{E}| / \mathbf{E}_{\mathbf{s r}(\mathbf{0 . 1})}$ & $\mathbf{u}|\mathrm{E}| \mathbf{E}_{\mathbf{s r}(\mathbf{0 . 1}-\mathbf{0 . 2})}$ & $\mathbf{u}|\mathrm{E}| \mathbf{E}_{\mathbf{s r}(>\mathbf{0 . 2})}$ \\
\hline Position 1 & $1.71 \%$ & $53.22 \%$ & $45.07 \%$ \\
\hline Position 2 & $1.17 \%$ & $8.51 \%$ & $90.32 \%$ \\
\hline Position 3 & $0.00 \%$ & $90.70 \%$ & $9.30 \%$ \\
\hline Position 4 & $55.51 \%$ & $29.28 \%$ & $15.21 \%$ \\
\hline
\end{tabular}

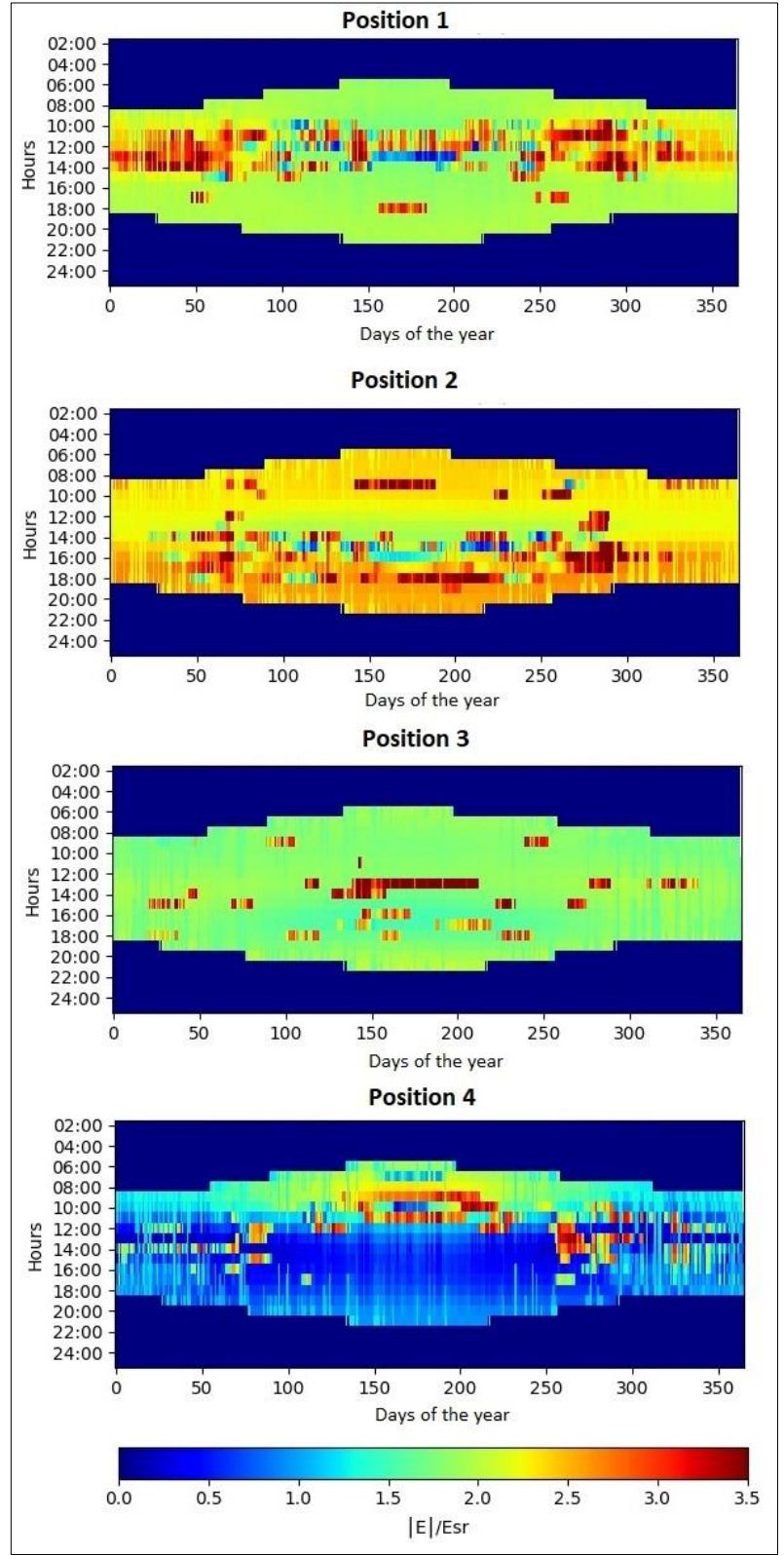

Figure 8: $|\boldsymbol{E}| / E_{\text {sr }}$ annual trends in positions 1, 2, 3 and 4 referred to the Atrium

The positions 1 and 3 present a $\mathrm{u}|\mathbf{E}| / \mathrm{E}_{\mathrm{sr}(0.1-0.2)}$ of $53.22 \%$ and $90.70 \%$, respectively. Also, when evaluating conditions outside this "useful" range, we can observe that positions 1 and 2 mainly have strong modeling conditions of $45.07 \%$ and $90.32 \%$, respectively. However, in point 4 , the percentage of annual occurrence in weak modeling condition is equal to $55.51 \%$.

In the dynamic analysis (see Figure 8), we can see that the extreme conditions are more dispersed than in the Peristyle. However, we can highlight point 1, where $|\mathbf{E}| / \mathrm{E}_{\text {sr }}$ values higher than 0.2 occur mainly in the autumn and winter period, during the first hours of the morning until noon. In relation to point 2 , a dispersion similar to the Peristyle is presented when considering the condition of $\mathrm{u}|\mathbf{E}| / \mathrm{E}_{\mathrm{sr}>0.2)}$ throughout the year, between noon to $6: 30$ p.m. On the other hand, point 3 presents the most constant 
condition throughout the year, highlighting a small value $(10 \%)$ in the summer months of $\mathrm{u}|\mathbf{E}| / \mathrm{E}_{\mathrm{sr}(>0.2)}$ between 12:00 p.m. and 2 p.m. Finally, position 4 presents a different behavior compared to the other positions, being characterized by conditions throughout the year mainly below the "useful" range, concentrating the strong modeling condition $\left(\mathrm{u}|\mathbf{E}| / \mathrm{E}_{\mathrm{sr}(>0.2)}\right)$ in the early hours of the morning until noon $(15.20 \%)$ during summer.

The observed annual trends of the $|\mathbf{E}| / \mathrm{E}_{\mathrm{sr}}$ can be explained considering the direction from which daylight reaches each considered point: the higher the incidence of direct sunlight is, the higher the $|\mathbf{E}| / \mathrm{E}_{\mathrm{sr}}$ values are.

For example, as for positions 2, receiving daylight from West, the highest values of $|\mathbf{E}| / \mathrm{E}_{\mathrm{sr}}$ are observed during the evening hours in all the seasons for the peristyle and in all the seasons except winter for the atrium. Conversely, for the position 4 receiving daylight from East, the highest values can be observed in both spaces during the first hours of the day especially in summer.

\section{Conclusions}

The authors of this work have previously produced several studies in this area (Monteolivaet al., 2018; Monteoliva \& Pattini, 2017; Bellia et al., 2017). At the moment, all methods evaluating the effects of light on modeling were used as ad hoc assessment according to a static approach.

This article presents a new look focused on the adaptation of the cubic illuminance to the dynamic paradigm, with the particularity of applying the dynamic methodology of useful modeling indices (UMIs) proposed by the authors in previous works, for the first time to the modeling indicator vector to scalar ratio $\left(|\mathbf{E}| / \mathrm{E}_{\mathrm{sr}}\right)$. This generates the possibility not only to evaluate the annual occurrence of "useful" modeling conditions -moderate modeling $\left(\mathrm{u}|\mathbf{E}| / \mathrm{E}_{\mathrm{sr}(0.1-0.2)}\right)-$, but also to assess and quantify default conditions $\left(\mathrm{u}|\mathbf{E}| / \mathrm{E}_{\mathrm{sr}(<0.1)}\right)$ and excess $\left(\mathrm{u}|\mathbf{E}| / \mathrm{E}_{\mathrm{sr}(>0.2)}\right)$ ones. It is important to consider that this dynamic methodology can be applied to other modeling indicators that arise from the information obtained from cubic illuminance, such as: vector to cylindrical illuminance ratio (Bean, 1978), and vertical to horizontal illuminance ratio (Love \& Navvab, 1994).

From these results it was possible to analyze in greater depth the dynamic behavior of daylight in two spaces with direct daylight penetration into the Villa, applying twodimensional metrics (sDA, $\mathrm{E}_{\mathrm{vertical}}$ ) and three-dimensional metrics $\left(\mathrm{u}|\mathbf{E}| / \mathrm{E}_{\mathrm{sr}(0.1-0.2)}\right)$. As a result of the analysis of twodimensional metrics, a similar behavior was obtained for $\mathrm{sDA}_{(10001 \mathrm{x}, 50 \%)}$ values between both spaces, with a difference between them lower than $10 \%$ in favor of the Peristyle. However, when evaluating the vertical $\left(E_{(x)}, E_{(-}\right.$ $\left.\left.{ }_{x}\right), E_{(y)}, E_{(-y)}\right)$ and horizontal $\left(E_{(z)}\right)$ illuminances in the selected positions, the Atrium is the space with greater availability of daylight. This greater availability of daylight is also evident in the analysis of the threedimensional metric useful vector to scalar ratio $\left(\mathrm{u} \mid \mathbf{E} / \mathrm{E}_{\mathrm{sr}(0.1-0.2)}\right)$, obtaining in Peristyle, only in position $4 \mathrm{a}$
$\mathrm{u}|\mathbf{E}| / \mathrm{E}_{\mathrm{sr}(0.1-0.2)}$ higher than $50 \%$ (57.33\%), while the other positions did not exceed 3\%. On the other hand, the Atrium presented in position 1 and $3, \mathrm{u}|\mathbf{E}| / \mathrm{E}_{\mathrm{sr}(0.1-0.2)}$ values of $53.21 \%$ and $90.69 \%$, respectively.

Beyond the application of UMIs, the paper demonstrates that the use of dynamic daylight simulations is a proper tool to study daylighting conditions in ancient buildings. First of all, daylight analysis is useful to better knowing the way ancient architects managed daylight in their buildings. The application of the same analysis typology to other spaces of the villa (and in other similar buildings) would allow understanding the relationship between the ancient building criteria and the necessity to harvest daylight, that was the principal light source, when electric light did not exist. Moreover, it would provide useful information about the luminous environment (both in quantitative and qualitative terms) which ancient people were used to.

Moreover, this analysis typology is useful to analyze what the current daylight conditions are, when excavations are visited nowadays. In this context the atria and the peristyles are particularly interesting, since they are sort of filtering spaces between inside and outside, allowing the passage of people from spaces characterized by significant light gradients. So, they represent a mean to strictly attenuate entering daylight and at the same time to allow visual adaptation, both when getting in and out the building. Indeed, Pompeii ruins, differently from most of the archeological excavations, that can be considered outdoor spaces, preserve in part their structure, meaning that a lot of buildings are equipped with original or rebuilt roofs. This determines that along the visit path of the ruins people continuously move from outdoor to indoor spaces and vice-versa and consequently they have to adapt to different lighting conditions. For this reason, some spaces appear really dark, whereas in others, the direct daylight entrance determines veiling effects on the painted walls, disturbing their view. Results of the daylight analysis can help in understanding the proper design strategies necessary to solve these problems: for example, the use of an electric lighting system integrating daylight also during day or the installation of proper shading devices.

The proposed research is only the first step to deepen the knowing of daylight use in ancient architectures by means of the most recent simulation techniques and parameters. Further studies are necessary in order to extend the proposed procedure to other daylit rooms in ancient domus and to other ancient buildings.

\section{References}

Ashdown, I. (1998). The virtual photometer: Modeling the flow of light. Proceedings from IESNA Annual Conference. San Antonio (US), 437-452 August 1998.

Bean A.R. (1978). Modeling indicators for combined side and overhead lighting systems. Lighting Research and Technology 10, 199-202. 
Bellia, L., Osanna, M. Spada, G., Mauro, A., Donzella, C., Fragliasso F., \& Stefanizzi, E. "Chromatic analysis of Roman frescoes in a Pompeiian domus" Proceedings from the XIII Conferenza del colore. Naples, Italy. 45 September 2017.

Berardi, U., \& Wang, T. (2014). Daylighting in an atriumtype high performance house. Building and Environment, 76, 92-104.

Boyce, P. (2013) Lighting quality for all. Proceeding from CISBE SLL Int. Light. Conf. Dublin (Ireland), 1-5 April 2013.

Cuttle, C. (1997). Cubic Illumination. Lighting Research and Technology 29, 1-14.

Cuttle, C. (2008). Lighting by Design (2nd edition). Architectural Press. Oxford (UK).

Cuttle, C. (2014). Research Note: A practical approach to cubic illuminance measurement. Lighting Research and Technology 46, 31-34.

European Committee for Standardisation (2011). Light and lighting - Lighting of work places - Part 1: Indoor work places ( EN 12464-1).

Illuminating Engineering Society of North America (2013). IES Spatial Daylight Autonomy (sDA) and Annual Sunlight Exposure (ASE). (IES LM-83-12).

Jacobs A. (2012). Radiance Tutorial. URL http://www.jaloxa.eu/resources/radiance/documentati on/docs/radiance_tutorial.pdf. Last access: $18^{\text {th }}$ January 2019

Kruisselbrink, T., Dangol, R., \& Rosemann, A. (2018). Photometric measurements of lighting quality: An overview. Building and Environment 138, 42-52.

Love, J.A., \& Navvab, M. (1994). The Vertical-toHorizontal Illuminance Ratio: A New Indicator of Daylighting Performance. Journal of the Illuminating Engineering Society 23, 50-61.

Lynes, J.A., Burt, W., Jackson, G.K., \& Cuttle, C. (1966). The flow of light into buildings. Transactions of the Illuminating Engineering Society, 31(3_IEStrans), 6591

Maiuri A. (1931). La Villa dei Misteri. Libreria dell Stato. Roma (ITA).

Molina, G., Vera, S., Bustamante, W. \& Bleicher, T.. (2008). Groundhog-SketchUpExtension for exporting Radiance models. URL https://extensions.sketchup.com/en/content/groundho g. Last access: $18^{\text {th }}$ January 2019

Monteoliva, J. M., Villalba, A., \& Pattini, A. (2018). Daylighting metrics: An approach to dynamic cubic illuminance. Journal of Daylighting, 5(2), 34-42.

Monteoliva, J.M., \& Pattini, A. (2017). New dynamic indicators for the evaluation of daylight on vertical and combined surfaces in interior spaces. Proceeding from Argentine Day of Lighting Technology. Mendoza (ARG) 11-14 November 2017.
Nabil, A., \& Mardaljevic, J. (2005). Useful daylight illuminance: a new paradigm for assessing daylight in buildings. Lighting Research \& Technology, 37(1), 41-57.

Paoli, U. E., Mondadori, Ed. Vita Romana. Usi, costumi, istituzioni, tradizioni. 2006.

Reinhart, C. F., Mardaljevic, J. \& Rogers, Z. (2006). Dynamic daylight performance metrics for sustainable building design. Leukos, 3(1), 7-31.

Ward, G., \& Rubinstein, F. (1988). A new technique for computer simulation of illuminated spaces. Lawrence Berkeley Laboratory Report 23042. 